\begin{tabular}{l}
\hline 綜 \\
\hline
\end{tabular}

\title{
米の消化吸收に關する交献 (I)
}

\author{
厚生省研究所 國民柴美部 \\ 大礒 敏 雄 \\ 緒言
}

古よ可我が國民は米を好んで食し之を所詡主食亡して尊重するの゙傳統は依然不變の睢会门几

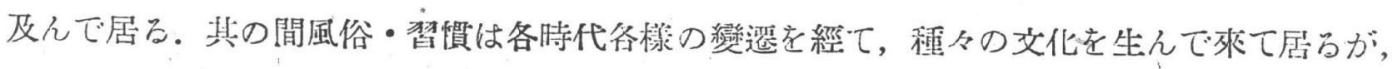

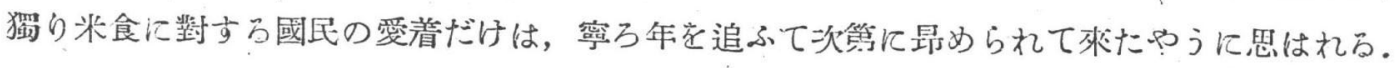

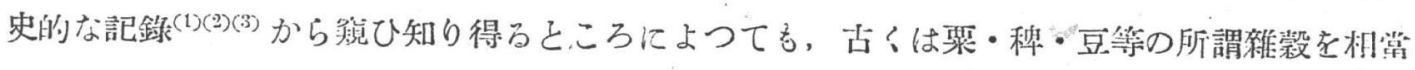

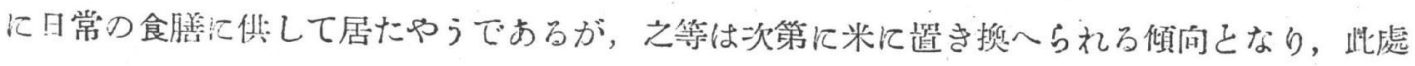
に我が國民の米江對方る異常な愛好性を見逃すことが出來ない，從つて我が國民の米作技術は

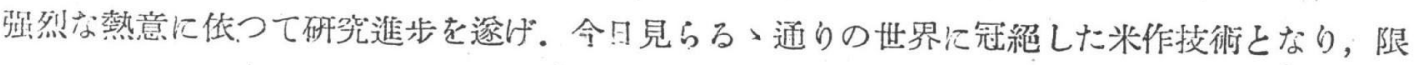
られたる狹小な上地より收檴される米つ量に於ても勿諭のこと質に於ても優秀なものとなつ

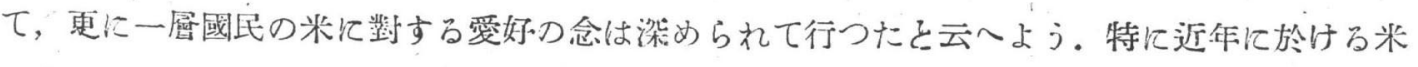

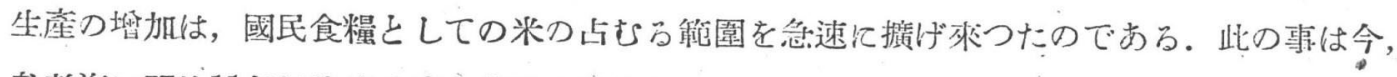

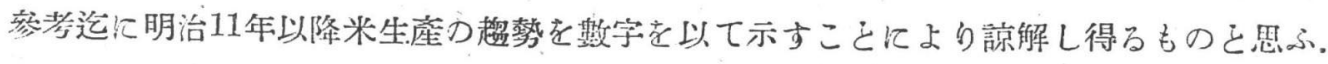

内地米生産の莬䇨 (4)

\begin{tabular}{|c|c|c|c|c|c|c|c|}
\hline 年: & 産 & 額 (石) & $\%$ & 作 付面 皘 (叮) & $\%$ & 反當收量(石) & $\%$ \\
\hline 明治11年 & & 32540 & 100 & 2489765 & 100 & 1.015 & 100 \\
\hline "2L年 & & 15583 & & 2685986 & & 1.439 & $\because$ \\
\hline " 31年 & & 37666 & & 2817624 & & 1.682 & \\
\hline " 41年 & & 33893 & 204 & 2922387 & 117 & 1.777 & 174 \\
\hline 大正 7 年 & & 0161 & & 3092798 & & 1.769 & \\
\hline 昭和 3 年 & & 3089 & & 3191736 & & 1.889 & \\
\hline " 13年 & & 65869092 & 260 & 3220729 & 130 & 2.040 & 200 \\
\hline
\end{tabular}

斯、の如き爿況であらから，我が國民の身體を造り上げ刃之を活動せしめる源の非常に多く の部分を米が供給して居る譯で, 米の持つ榮養的な價値は, 我が國民つ䌡力, 更に强く云へば

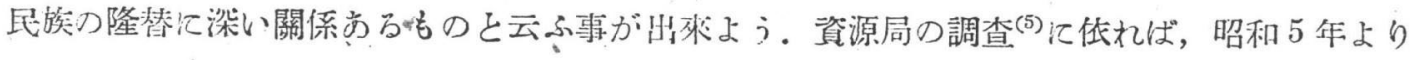

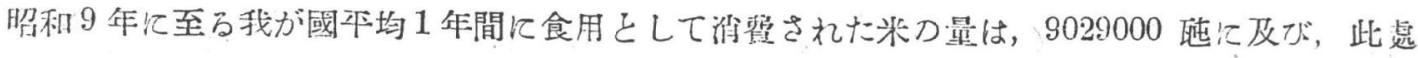

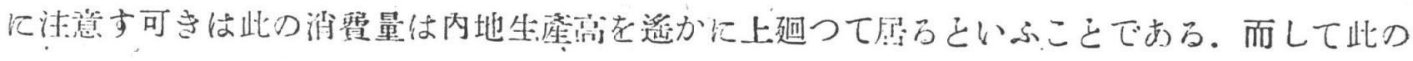


米の演ず号榮養方面つ主な役割を見るに，攝取總熱量中の $51.3 \%$ 老占め，攝取總蛋白質量の

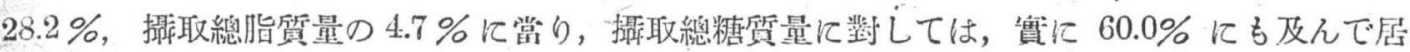
ることであり，米の含有する無機質の量はたとへ価少とは云へ，攝取總無機質量の $13.9 \%$ 迄

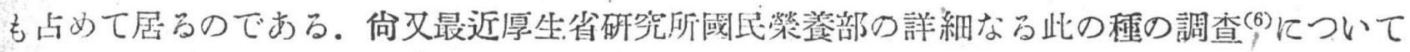
見らならば，米の占むる榮養的の地位は，熱量に於て $59.0 \%$ ，蛋白質量沉於て $39.4 \%$ ，脂

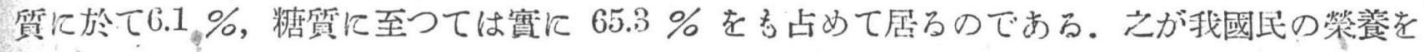
据つて居る實に一品の食品であることに想ひ至るならば, 米の受持つ榮養的地位の如何に大な るかを誰しも痛感せずては居られないであらう。

然し乍ら米の持つ榮養價値そのものを, 直ちに我國民の笑養と結で付けることは少し早計で あつて，その間江種々な問題が介在するのである。其つ中最も大切なことは米の消化吸收と云 ふ問題である。之は例へて謂ふならば, 或る人が金の鍰石を所有して居らからと云つて, 所有 する金の量は其の鐄石て含まれて居方金の總量と云ふ翋てはゆかないで，鋽石より探り出し得

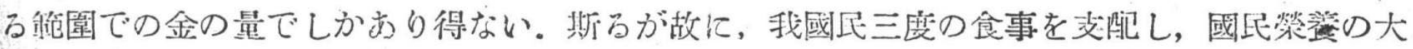

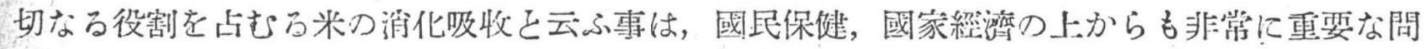
題たるを失はない：

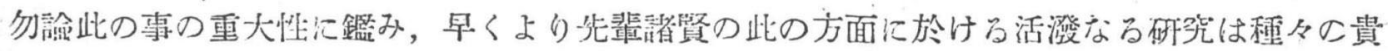

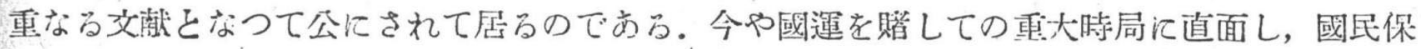

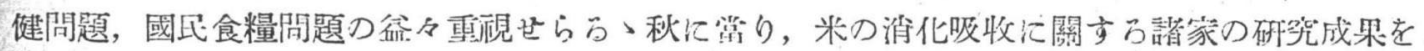
通覽して同學の士の參考江供するのも强ち徒爾でないと思はれるので，以下夫々原著より重姴

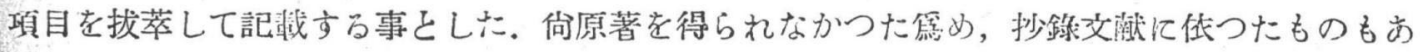
らから內容の詳細汇亘つては, 夫々の原著沉就て見て頂き度小ので方々。

\section{1. 消化 吸收試 驗}

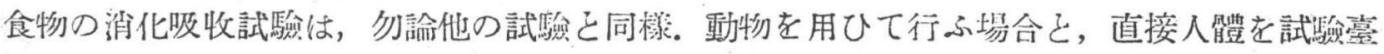
とする場合との二つあらが，此つ問題の性質上固より其の試驗は，後者を選ぶことが適常であ

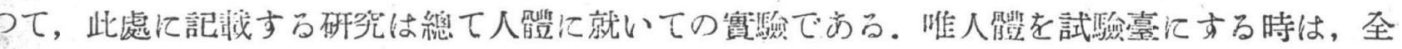
く同一條件の試驗管內沉於ける操作之は異り, 種々の外部的・内部的條件沉影響される事か甚 だ多いのであるから，可成的同一條件下に行つても全く间一結果を期行出來ぬこと之亦當然と

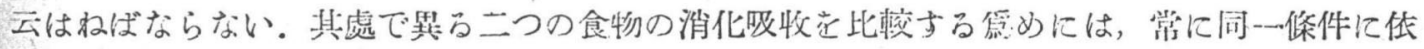
る同一被驗者てついて行はれたものを比較しふければ飛んだ誤謬孝招くこと、なるのである。

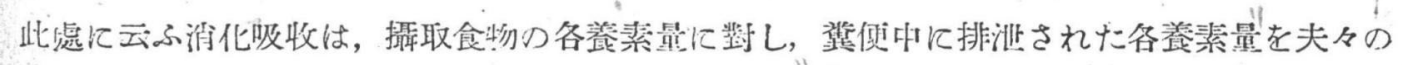
搠取量から減じた量を以て，消化吸收量こ見做して其つ比率を求めたものであつて，其のうち

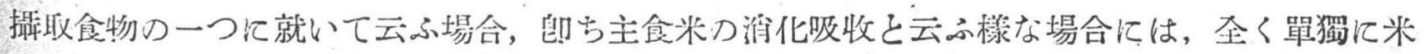
のみを攝ると云ふ場合もあるのではあらが，之ば然理が伴す長續きせぬため反つて，生理的に 


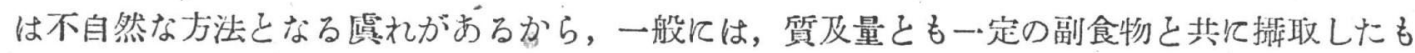

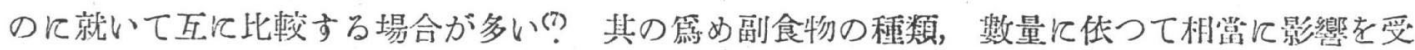
けるここにならから，饱く迄も同一條件下の試驗成績沉ついてのみ比較對照する箓が必要であ

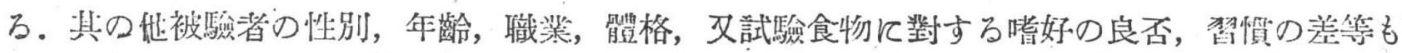
大切な條件であらうし, 試驗期閒, 季節, 天候, 氣温等の生活環境や，攝取食物の量及び質，

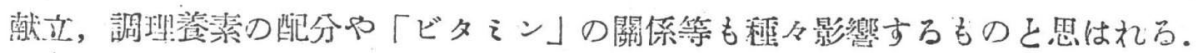

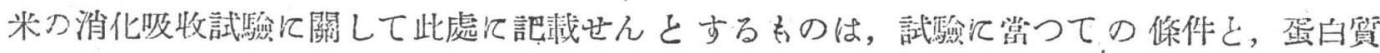

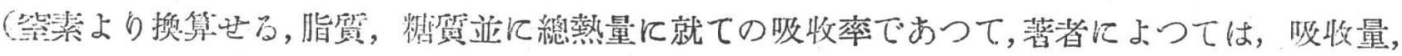

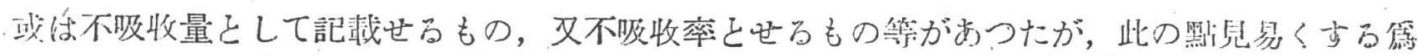
め統一して一律沉收率を用ひた。

\section{2. 白米の消化吸收}

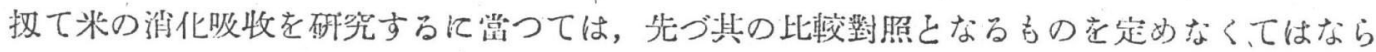
ない.日常一般沉行はれら米の食用型式としては, 第一に米えのものの搗精沉䅜々の度合が存

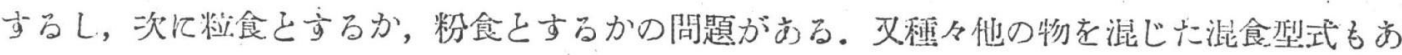

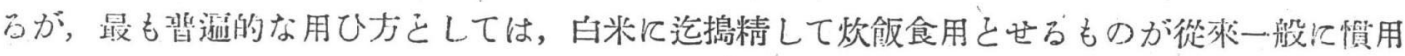
- 第 1 表(I)

\begin{tabular}{|c|c|c|c|c|c|c|c|c|c|}
\hline \multirow{2}{*}{ 菳䗂 } & \multicolumn{2}{|c|}{ 被 } & 檢 & 惹 & \multirow{2}{*}{ 年 } & \multirow{2}{*}{ 季: 箕 } & \multirow{2}{*}{ 期 間 } & \multirow{2}{*}{\multicolumn{2}{|c|}{ 研 究“者 }} \\
\hline & 職 & 袖 & 人占 & 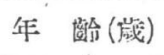 & & & & & \\
\hline 1 & \multicolumn{2}{|c|}{ - } & 1 & - & 明治36年 & \pm 月 & 7日 & 黑 & $\bar{\Pi}^{(8)}$ \\
\hline 2 & 鉣 & I & 2 & $20-24$ & 大正元年 & 3月 & $7 \mathrm{H}$ & \multicolumn{2}{|c|}{ 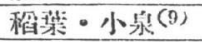 } \\
\hline 3 & 稒 & 夫 & 2 & $28-30$ & 11 & 1 & $"$ & & \\
\hline$t$ & \multicolumn{2}{|c|}{-} & 2 & - & 大正3年 & - & 4 月 & \multicolumn{2}{|c|}{ 小泩・柔(10) } \\
\hline 5 & \multicolumn{2}{|c|}{ 䂺究者自身 } & 1 & - & " & - & $2 \theta$ & 古 & $M_{1}^{(11)}$ \\
\hline 6 & & $I$ & 1 & & 大正 9 年 & 10月 & $7 \cdot \theta$ & 坂 & 本(12) \\
\hline 7 & \multicolumn{2}{|c|}{$"$} & 1. & & " & "I & 11 & & \\
\hline 8 & \multicolumn{2}{|c|}{ "I } & 1. & & 11 & $"$ & "I & & \\
\hline$y$ & \multicolumn{2}{|c|}{11} & 1 & & 11 & " & 11 & \multicolumn{2}{|c|}{ "1 } \\
\hline 10 & \multicolumn{2}{|c|}{ 证究者自身 } & 1 & - & "1 & 2月 & 4日 & 古 & $\mathrm{S}^{(\mathrm{L} 3)}$ \\
\hline 11 & \multicolumn{2}{|c|}{ " } & 1 & - & " & $" 1$ & 3 日 & \multicolumn{2}{|c|}{ "I } \\
\hline 12 & \multicolumn{2}{|c|}{-} & 2 & - & 大正11年 & - & 5 日 & 濢 & 村 (14) \\
\hline 13 & \multicolumn{2}{|c|}{ 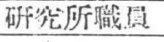 } & 3 & $2 t-27$ & 11 & 2月 & $2 \theta$ & 杉 & 本 $\{15\rangle$ \\
\hline 14 & \multicolumn{2}{|c|}{ " } & 5 & $24-27$ & 11 & 5月 & 11 & & \\
\hline 15 & \multicolumn{2}{|c|}{ "I } & 5 & 11 & 11 & 1 & $"$ & & \\
\hline 16 & \multicolumn{2}{|c|}{11} & $t$ & $24-27$ & " & 6 月 & " & & \\
\hline 17 & \multicolumn{2}{|c|}{11} & 5 & $26-30$ & 大正 12 年 & 2月. & 11 & & \\
\hline 18 & \multicolumn{2}{|c|}{$"$} & 5 & $21-25$ & " & 3月 & $" 1$ & & \\
\hline 19 & \multicolumn{2}{|c|}{$"$} & 3 & $25-27$ & " & 4月 & $" 1$ & & \\
\hline 20 & \multicolumn{2}{|c|}{11} & 5 & $17-21$ & "I & 5月 & $" 1$ & & \\
\hline $2 i$ & \multicolumn{2}{|c|}{ " } & 5 & $27-35$ & $" 1$ & 6月 & $"$ & & \\
\hline 22 & & & 5 & $17-27$ & 11 & 11月 & $" 1$ & . & \\
\hline 23 & & & $t$ & $27-28$ & 大正13年 & 9月 & $"$ & & \\
\hline $2-t$ & & & 5 & $17-21$ & 大正12年 & 11月 & $" 1$ & & \\
\hline 25 & 學 & 生 & 4 & $21-25$ & 昭和 5 年 & 1月. & $" 1$ & & \\
\hline 26 & & & 4 & $20-27$ & 昭和15年 & 11 & $"$ & 터 & 村 $(16)$ \\
\hline 27 & & & 4 & 1 & 1 & $2 月$ & $"$ & & \\
\hline
\end{tabular}

$(4)$ 
第， 1 表（II）

\begin{tabular}{|c|c|c|c|c|c|c|c|c|}
\hline \multirow{2}{*}{ 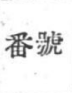 } & \multirow{2}{*}{ 主 食 $\frac{\text { 量 }}{(\mathrm{g})}$} & \multirow{2}{*}{$\begin{array}{r}\text { 主食熱量 } \\
\text { (Cal) }\end{array}$} & \multirow{2}{*}{$\begin{array}{l}\text { 副食樊量 } \\
\text { (Cal) }\end{array}$} & \multirow{2}{*}{$\begin{array}{l}\text { 總㳺昌: } \\
\text { (Cal) }\end{array}$} & \multicolumn{2}{|c|}{ 吸 } & \multicolumn{2}{|c|}{ 率 $(\%)$} \\
\hline & & & & & 蛋白質 & 脂 貿 & 惦 質 & 熱 量 \\
\hline 1 & $6 \dot{6} 0$ & 2310 & 250 & 2560 & 89.36 & 76.86 & 99.90 & - \\
\hline 2 & 768 & 2499 & 125 & 2634 & 82.42 & 80.43 & 99.81 & - \\
\hline 3 & 750 & 2523 & 306 & 2829 & 79.20 & 61.63 & 99.77 & - \\
\hline 4 & - & - & - & - & 71.84 & 40.16 & 99.42 & - \\
\hline 5 & - & - & - & - & 81.92 & 82.82 & 99.05 & - \\
\hline 6 & 2121 (领) & - & - & $363 \mathrm{~L}$ & 75.49 & 80.05 & 99.65 & 96.59 \\
\hline 7 & 1901 (飯) & - & - & 3253 & 75.23 & 79.57 & 99.77 & 96.56 \\
\hline 8 & 1987 (飯) & - & - & 3406 & 79.31 & 77.11 & 99.69 & 96.71 \\
\hline 9 & 1585 (领) & - & - & 2770 & 77.04 & 79.57 & 99.57 & 46.38 \\
\hline 10 & 523 & - & - & 1861 & 82.20 & 84.50 & 99.80 & 98.20 \\
\hline 11 & 484 & - & - & 1752 & 69.20 & 69.70 & 99.80 & 96.70 \\
\hline 12 & - & - & - & - & 93.61 & 41.81 & 99.62 & - \\
\hline 13 & 528 & 1848 & $65 \hbar$ & 2504 & 88.66 & 91.61 & 99.66 & 97.42 \\
\hline 14 & 563 & 1969 & 656 & 2625 & 85.33 & 85.75 & 99.67 & y7.03 \\
\hline 15 & 547 & 1914 & 656 & 2570 & 87.13 & 88.91 & 99.70 & 97.38 \\
\hline 16 & 493 & 1724 & 656 & 2380 & -84.91 & 85.79 & 99.67 & 96.75 \\
\hline 17 & 519 & 1815 & 592 & 2407 & 81.42 & 85.89 & 99.50 & 95.76 \\
\hline 18 & 458 & 1603 & 592 & 2195 & 86.58 & 83.68 & 99.59 & 96.66 \\
\hline 19 & 522 & 1827 & 592 & 2419 & 85.75 & 91.66 & 99.77 & 96.75 \\
\hline 20 & 595 & 2083 & 592 & 2675 & 86.53 & 90.41 & 99.72 & 97.38 \\
\hline 21 & 665 & 2330 & 592 . & 2922 & 82.34 & 90.62 & 99.72 & 96.88 \\
\hline 22 & 503 & 1863 & 718 & 2581 & 81.91 & 90.74 & 9 - .65 & 96.55 \\
\hline 23 & 572 & 2003 & 612 & 2615 & 84.62 & 91.10 & 99.70 & 97.03 \\
\hline 24 & 516 & 1806 & 718 & 2524 & 84.12 & 91.71 & 99.57 & 96.70 \\
\hline 25 & 450 & 1575 & 872 & $2 \pm 47$ & 89.85 & 79.18 & 99.66 & 97.21 \\
\hline 26 & 480 (最高) & - & - & 2621. & 84.62 & 82.47 & 99.58 & 95.96 \\
\hline 27 & " & - & - & 2568 & 86.46 & 80.93 & 99.65 & 90.27 \\
\hline
\end{tabular}

されて居たところのものであるから，何れの試驗を行ふにしても先づ白米を其の對照に選ぶ場

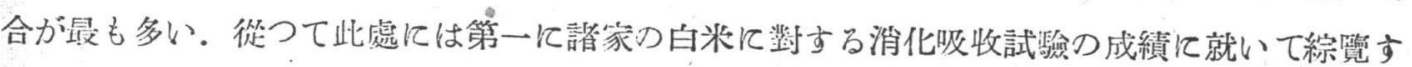
ること、した。

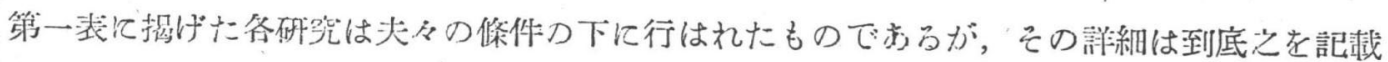

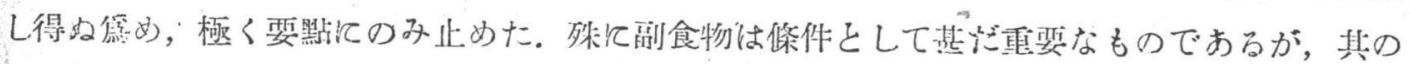

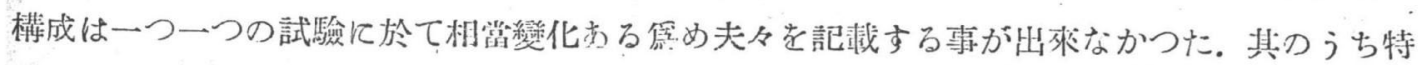
て他と著しく異りたるものを見るならば，第し號は，副食こして喽噌汁のみを供したらもので

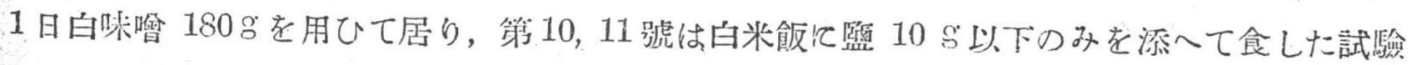
で，他は總て夫多被檢者の常用汇近い副食老硔してて居る。

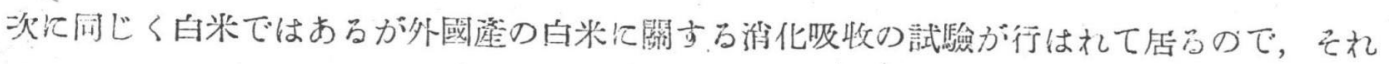

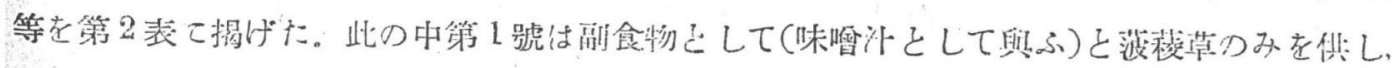
他は通常刀副食物が副へられて居る。

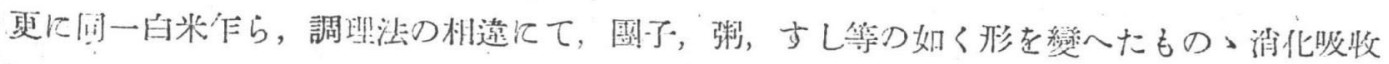

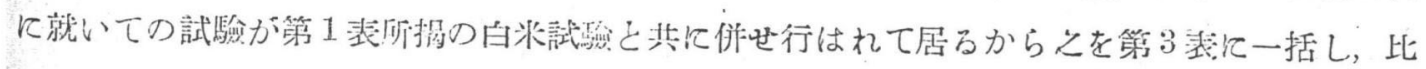

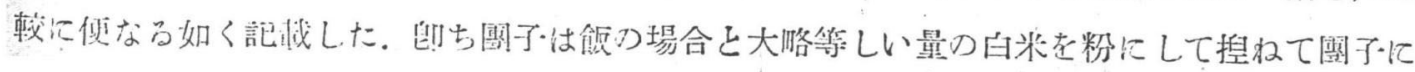


第 2 表 (I)

\begin{tabular}{l}
\hline \hline 番號 \\
\hline 2
\end{tabular}

圓めたもので，副食物は對照と全く同一物が供されてるる，弱は白米飯の場合の紿 $1 / 4$ 量を以 て粥となしたもので，從つて其て攝取熱量も $1 / 2$ 以下となつてるる。但し副食物は全く同じで

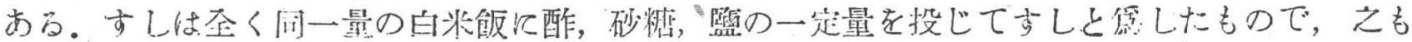

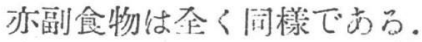

$$
\text { 第 } 3 \text { 表 }
$$

\begin{tabular}{|c|c|c|c|c|c|c|c|c|c|c|c|}
\hline \multirow{2}{*}{ 乘路 } & \multirow{2}{*}{ 試驗主食' } & \multicolumn{3}{|c|}{ 吸 } & \multicolumn{4}{|c|}{ 率 } & \multirow{2}{*}{ 矿 } & \multirow{2}{*}{ 究 } & \multirow{2}{*}{ 煍 } \\
\hline & & 蛋 白 質 & ，脂 & 質 & 粘 & 質 & 浮 & 量 & & & \\
\hline 17 & 白 米 & 81.42 & \multicolumn{2}{|c|}{85.89} & \multicolumn{2}{|c|}{99.50} & \multicolumn{2}{|l|}{95.76} & 杉 & \pm & 本 \\
\hline 31 & 白米国子 & 85.10 & \multicolumn{2}{|c|}{90.91} & \multicolumn{2}{|c|}{99.67} & \multicolumn{2}{|l|}{96.86} & & \multicolumn{2}{|l|}{11} \\
\hline 19 & 白 米 & 85.75 & \multicolumn{2}{|c|}{91.66} & \multicolumn{2}{|c|}{99.77} & \multicolumn{2}{|l|}{96.75} & \multicolumn{3}{|c|}{ "11 } \\
\hline 32 & 槛 & 80.62 & \multicolumn{2}{|c|}{90.89} & \multicolumn{2}{|c|}{99.21} & \multicolumn{2}{|l|}{93.43} & \multicolumn{3}{|c|}{11} \\
\hline 21 & 白 & 82.34 & \multicolumn{2}{|c|}{90.62} & \multicolumn{2}{|c|}{99.72} & \multicolumn{2}{|l|}{96.88} & \multicolumn{3}{|c|}{ "1" } \\
\hline 33 & す & 84.24 & & & & & 97.32 & & \multicolumn{3}{|c|}{$" 1$} \\
\hline
\end{tabular}

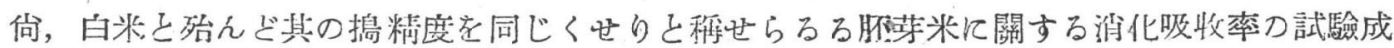

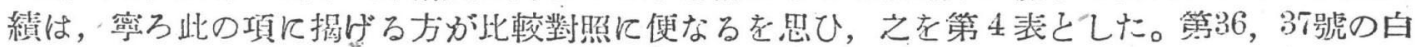

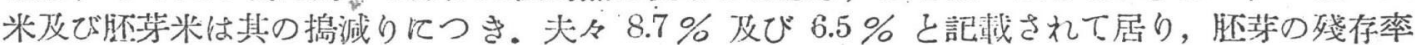

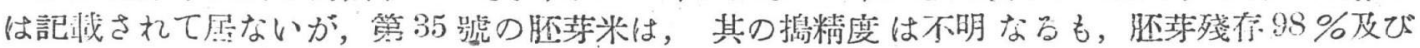
$77 \%$ のものを用ひげ旨記されてるる。

第 4 昶 (I)

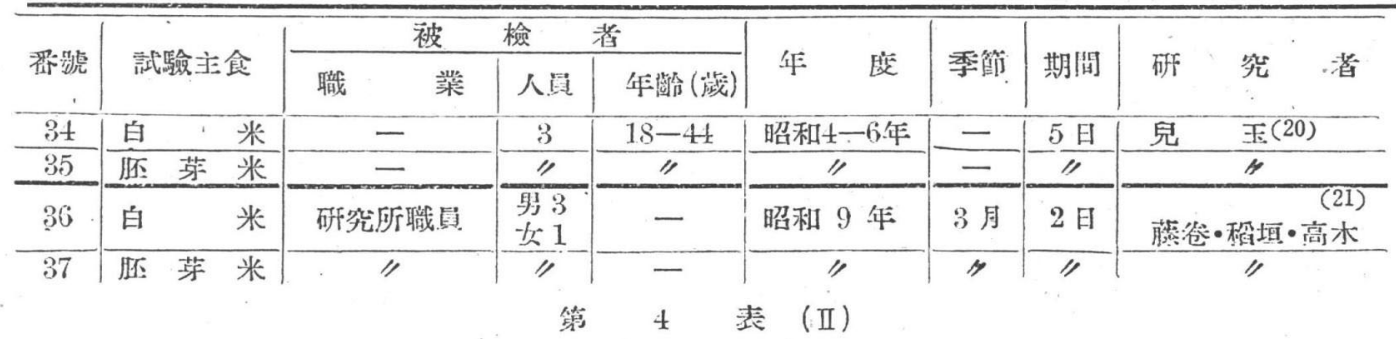

\begin{tabular}{|c|c|c|c|c|c|c|c|c|}
\hline \multirow{2}{*}{ 㺼䠈 } & \multirow{2}{*}{ 主食照 } & \multirow{2}{*}{$\begin{array}{c}\text { 主食钽量 } \\
\text { (Cai) }\end{array}$} & \multirow{2}{*}{$\begin{array}{c}\text { 副食然昂: } \\
(\mathrm{G}+\mathrm{l})\end{array}$} & \multirow{2}{*}{$\begin{array}{l}\text { 總热棐 } \\
\text { (Cal) }\end{array}$} & \multicolumn{2}{|c|}{ 昅 } & \multicolumn{2}{|c|}{ 率 (\%) } \\
\hline & & & & & 狵白質 & 脂 貿 & 楛 & 熟 \\
\hline 34 & 618 & 2161 & 407 & 25687 & 83.70 & 85.60 & 99.80 & - \\
\hline 35 & 643 & 2223 & $40: 3$ & 2626 & 84.20 & 82.20 & 99.70 & - \\
\hline 36 & 1318 (做) & - & - & - & 80.53 & 83.80 & 99.65 & $=$ \\
\hline 37 & $13+4(1 /)$ & - & - & - & 37.73 & 86.79 & 99.67 & - \\
\hline
\end{tabular}

